\title{
وضع مستويات معيارية لبعض القياسات الجسمية للاعبات الدوري العراقي الممتاز
}

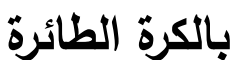

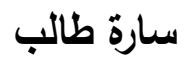 \\ كلية التربية البننية وعلوم الرياضية - جامعة بغاد \\ Sara.taleb@yahoo.com
}

(00964) 07700442290

\author{
أ. أ.د. سماح نورالدين عيسى \\ كلية التربية البننية وعلوم الرياضية -جامعة بغداد \\ smaah1992@yahoo.com
}

(00964) 07713661391

\begin{abstract}
مستخلص البحث باللغة العربية
تكمن أهمية البحث في وضع درجات ومستويات معيارية لبعض المتغيرات الجسمية للاعبات الدوري العراقي الممتاز بالكرة الطائرة ، أما مشكلة البحث فتتلخص بعدم وجود درجات ومستويات معيارية يمكن الاعنماد عليها لتحديد القياسات الجسمية الخاصة بلاعبات الكرة الطائرة في العراق، ويهدف البحث الى التعرف على مستوى بعض القياسات الجسمية ووضع درجات ومستويات معيارية لها، وتم اختيار المنهج الوصفي بالاسلوب المسحي لملائمته وموضع الدراسة، واثتملت الدراسة

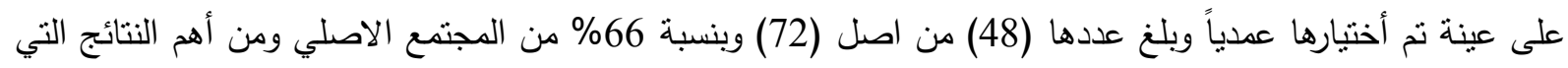

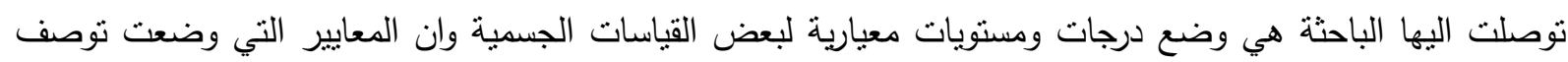

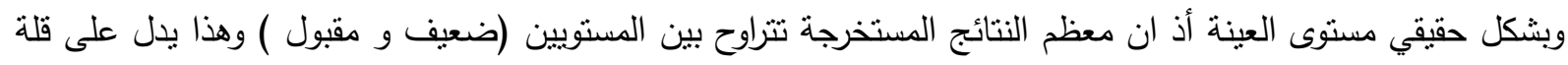

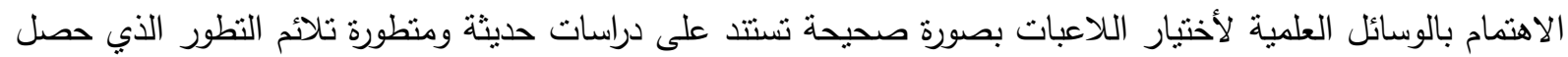

الكلمات المفتاحية: المستويات المعيارية ، القياسات الجسمية ، الكرة الطائرة.
\end{abstract}

\section{ABSTRACT \\ Establishing Criteria Levels For Some Anthropometric Measurement for Volleyball Primer League Female Players}

\author{
Asst. Pror. Dr. Samah Noraldeen Iesa \\ College of Physical Education and Sports \\ Sciences - University of Baghdad
}

Sara Talib

The importance of the research lies in developing criteria and levels for some physical variables for Iraqi volleyball Premier League. The problem of research lies in the lack of criteria and levels to determine anthropometric measurements and establishing degrees and criteria levels. The researchers used the descriptive methods on (48) out of (72) and $66 \%$ of the original society. The most important results reached by the researcher was the development of degrees and standard levels for some anthropometric measurements and that the standards that have been developed and describe the real level of the sample since most of the results extracted between the levels (weak and acceptable) and this indicates the lack of interest in the scientific means of choosing the players correctly based on recent studies.

Keywords : standard levels, anthropometric measurements, volleyball. 
تعد لعبة الكرة الطائرة واحدة من اجمل الالعاب الجماعية في عصرنا الحالي والتي شهدت مؤخراً تطوراً ملحوظاً وبكافة المستويات المهارية و التدريبية والخططية والتكتيكية ، وان هذا التطور الحاصل جاء نتيجة العديد من العيدة الدراسـات حول اهم المحاور والاسس التي تستند عليها هذه اللعبة، فكما هو معروف تعدد مهارات الكرة الطائرة وتتوعها من مهارات

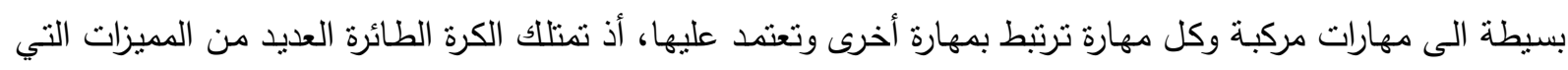
تختص بها مما اعطى اللعبة ذلك الطابع المشوق والممتع لممارستها وهذه الخاصية جميلة جداً والتي ميزت الكرة الطائرة عن غيرها من الالعاب الجماعية وهو قدرة اللاعبين قصار القامة بالاشتراك في اللعب على المستوى العالمي او المحلي

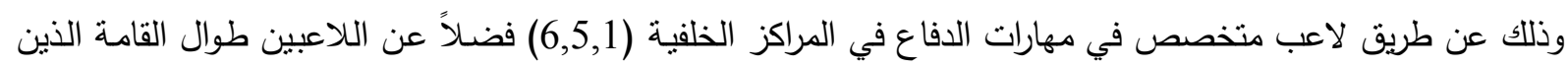

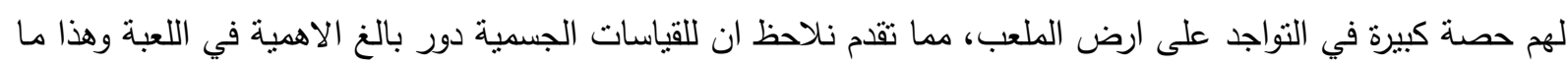

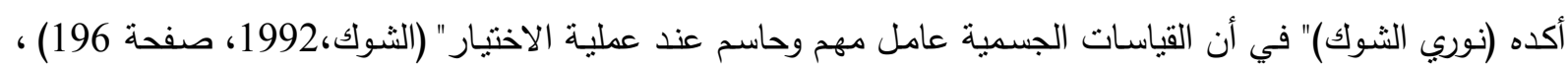

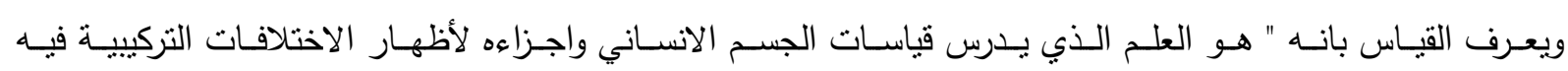
(ابراهيم،2001، صفحة 275) ، لذا فأن تتوع مراكز اللعب في الكرة الطائرة من ضـارب مركز 4 وضارب مركز 2 فضـاً

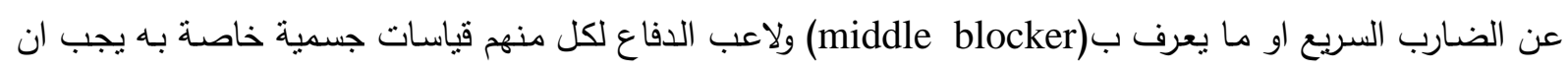
تتوفر في كل لاعب وحسب تخصصسه من اجل الوصول الى الاداء المثالي والجيد، وان للمعابير من درجات ومستويات

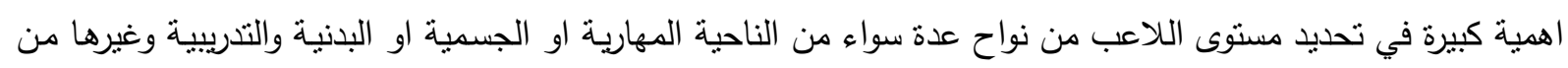

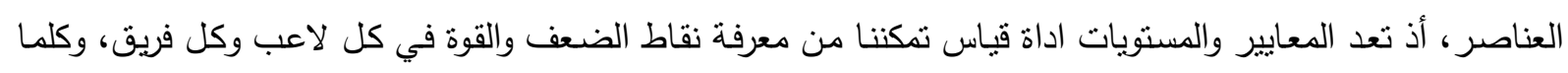
ازداد اهتمامنا بالمعايير وذلك عن طريق دراستها وتطويرها بصورة مستمرة زاد نطور الاداء في اللعبة ومن هنا تكمن أهمية البحث في وضع درجات ومستويات معيارية وفق بعض القياسات الجسمية للاعبات الدوري العراقي المتاز بالكرة الطائرة

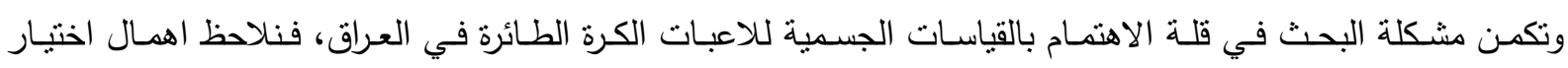
مواصفات جسمية صحيحة تتلائم مع تخصص كل لاعبة في الملعب، ولهذا وجب علينا وضع درجات ولات ومستويات معيارية

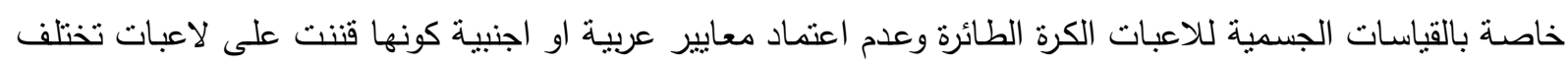
مواصفاتهم الجسمية عن لاعباتتا في عراقنا الحبيب. وتلخصت اهداف البحث في التعرف على مستوى بعض القياسات

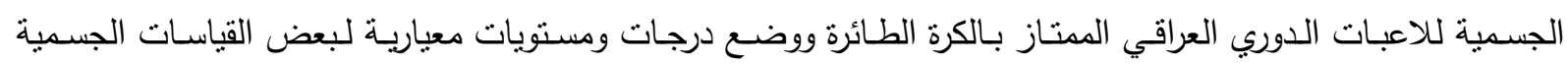

للاعبات الدوري العراقي المتاز بالكرة الطائرة .

منهج البحث:

المنهج هو "الطريق العلمي الذي يسلكه الباحث في حل مشكلة بحثه، فطبيعة المشكلة تقرض منهجا معينا للوصول إلى الحقيقة" (الثوك وفتحي، 2004، صفحة 71) ، وعليه استخدم الباحث المنهج الوصفي بالاسلوب المسحي لملائمته لطبيعة البحث . وتم اختيار مجتمع البحث المتمثل بأندية الدوري العراقي الممتاز بالكرة الطائرة للسبدات والبالغ عددها أحدى عشر نادي ( امانة بغداد ، الثباب ، افروديت ، قرة قوش ، سنحاريب ، بيشمركة ، آكاد ، سولاف ، طق طق ، كويا ، خاك )، اما عينة

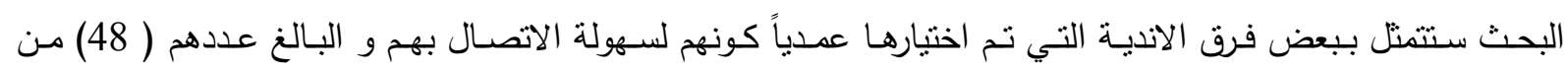

اصل(72) وبنسبة 66\% من مجتمع البحث وكما موضح في الجدول (1 ). 
مجلة كلية التربية الرياضية / جامعة بغداد ** المجلد الحادي والثلاثون* العدد الثالث * 2019. جدول (1) يبين تفاصيل عينة البحث

\begin{tabular}{|c|c|c|c|c|}
\hline النسبة المئوية للاعبات في الاندية & عدد اللاعبات في كل نادي & 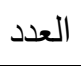 & الاندية & 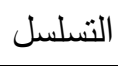 \\
\hline$\% 80$ & 10 & 8 & امانة بغداد & 1 \\
\hline$\% 50$ & 16 & 8 & الثباب & 2 \\
\hline$\% 57$ & 14 & 8 & قرة قوش & 3 \\
\hline$\% 100$ & 8 & 8 & سنحاريب & 4 \\
\hline$\% 66$ & 12 & 8 & برايتي & 5 \\
\hline$\% 66$ & 12 & 8 & آكاد & 6 \\
\hline$\% 100$ & 72 & 48 & 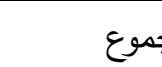 & \\
\hline
\end{tabular}

الادوات المستخدمة: شريط قاس متري جلدي لأخذ القياسات الجسمية بطول 2م وسمك 2 سم، واستمارة تقريغ البيانات،

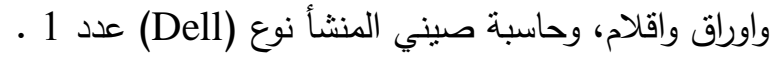
اذ نم عرض بعض القياسات الجسمية على مجموعة من الخبراء والمختصين، حيث اعتمدت الباحثة على نسبة اتفاق

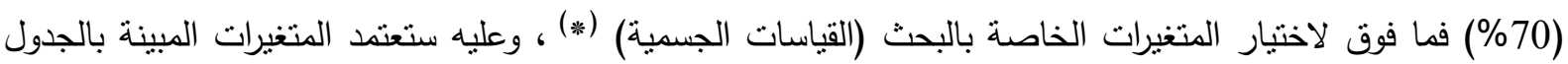

جدول (2) الأهمية النسبية للمؤشرات الجسمية ( الانثروبومتريه ) وحسب رأي (10) خبراء

\begin{tabular}{|c|c|c|c|c|}
\hline \multicolumn{2}{|c|}{ القبول بالترشيح } & \multirow{2}{*}{ الأهمية النسبية } & \multirow{2}{*}{ القياسات الجسميه المرشحه } & \multirow{2}{*}{$ت$} \\
\hline كلا & نعم & & & \\
\hline & 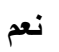 & 86,66 & 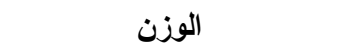 & 1 \\
\hline & نعم & 93,33 & الطول الكلي & 2 \\
\hline & نعم & 86,66 & طول الذراع( يمين _ يسار ) & 3 \\
\hline & 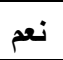 & 96,66 & طول الرجلين & 4 \\
\hline & 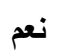 & 70 & طول الجذع من الجلوس & 5 \\
\hline \multirow[t]{2}{*}{ كلا } & & 68 & الطول الكلي والذراعان عالياً & 6 \\
\hline & نعم & 73,33 & طول الكف & 7 \\
\hline \multirow[t]{6}{*}{ كلا } & & 56 & طول العضد & 8 \\
\hline & 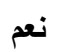 & 86 & طول الفذذ & 9 \\
\hline & 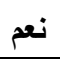 & 73,33 & طول الساق & 10 \\
\hline & 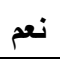 & 75,88 & عرض الصدر & 11 \\
\hline & نعم & 86 & عرض الحوض & 12 \\
\hline & 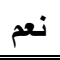 & 77,78 & عرض الكتقين & 13 \\
\hline كلا & & 60 & محيط الصدر شهيق & 14 \\
\hline \multirow[t]{5}{*}{ كلا } & & 66 & محيط الصدر زفير & 15 \\
\hline & 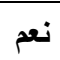 & 80 & محيط الساق & 16 \\
\hline & نعم & 86,66 & محيط العضد & 17 \\
\hline & 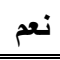 & 77,80 & محيط الفخذ & 18 \\
\hline & 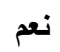 & 80 & محيط الحوض & 19 \\
\hline كلا & & 50 & محبط الرقبة & 20 \\
\hline
\end{tabular}


مجلة كلية التربية الرياضية / جامعة بغداد * المجلد الحادي والثلاثون ** العدد الثالث * 2019.

جدول (3) الوصف الإحصائي لمواصفات عينة البحث في القياسات الجسمية

\begin{tabular}{|c|c|c|c|c|c|c|c|}
\hline الالتواء & الانعياري & الكسابي & $ت$ & الالتواء & المعياري & الحسابي & $ت$ \\
\hline .880 & 3.63126 & 44.8229 & عرض الكتفين & .409 & 8.23327 & 60.4792 & الوزن \\
\hline .804 & 2.45085 & 38.6875 & عزض الصدر & $.5104-$ & 15.81171 & 162.2292 & الطول الكلي \\
\hline .326 & 3.14767 & 36.5833 & عرض الحوض & .235 & 3.25341 & 66.6042 & طول الذراع \\
\hline .347 & 4.48619 & 37.2083 & محيط العضد & .645 & .82130 & 18.4688 & طول الكف \\
\hline 699 & 4.53278 & 28.0833 & محيط الحوض & -.156- & 3.80160 & 63.1250 & طول الجذع \\
\hline 1.560 & 8.33792 & 89.3958 & محيط الفخذ & 1.332 & 7.64644 & 91.0000 & طول الرجلين \\
\hline 1.294 & 6.07693 & 55.4167 & محيط الساق & .982 & 4.58934 & 45.9583 & طول الفخذ \\
\hline & & & & .409 & 8.23327 & 60.4792 & طول الساق \\
\hline
\end{tabular}

جدول (4) المستويات المعيارية المعدلة لنتائج القياسات الجسمية

\begin{tabular}{|c|c|c|c|c|c|c|c|c|c|c|}
\hline اللالة & قيمة مريع & 90 اكثر من & 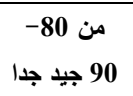 & من 70 جيد & من 60 -60 70 & من 50 مقبول & م0 50 ضعيف & اقل من جدا 40 & & القياسات \\
\hline \multirow{2}{*}{ معنوي } & \multirow{2}{*}{64.29301} & 0 & 0 & 3 & 4 & 12 & 24 & 5 & تكرار & \multirow{2}{*}{ الوزن } \\
\hline & & 0 & 0 & $6.3 \%$ & $8.3 \%$ & $25.2 \%$ & $\mathbf{5 0 \%}$ & $10.4 \%$ & النسبة \% & \\
\hline \multirow{2}{*}{ معنوي } & \multirow{2}{*}{109.2106} & 0 & 0 & 0 & 2 & 28 & 17 & 1 & تكرار & \multirow{2}{*}{ الطول الكلي } \\
\hline & & 0 & 0 & 0 & $4.2 \%$ & $\mathbf{5 8 . 8 \%}$ & $35.7 \%$ & $2.1 \%$ & النسبة \% & \\
\hline \multirow{2}{*}{ معنوي } & \multirow{2}{*}{53.50111} & 0 & 0 & 0 & 6 & 20 & 14 & 8 & تكرار & \multirow{2}{*}{ طول الذراع } \\
\hline & & 0 & 0 & 0 & $12.5 \%$ & $42 \%$ & $29.4 \%$ & 16.8 & النسبة \% & \\
\hline \multirow{2}{*}{ معنوي } & \multirow{2}{*}{60.20959} & o & o & 0 & 8 & 13 & 22 & 5 & تكرار & \multirow{2}{*}{ طول الكتف } \\
\hline & & 0 & 0 & 0 & $16.8 \%$ & $27.3 \%$ & $46.2 \%$ & $10.4 \%$ & النسبة \% & \\
\hline \multirow{2}{*}{ معنوي } & \multirow{2}{*}{50.87606} & 0 & 0 & 0 & 7 & 16 & 18 & 7 & تكرار & \multirow{2}{*}{ طول الجذع } \\
\hline & & 0 & 0 & 0 & $14.6 \%$ & $33.6 \%$ & $37.8 \%$ & $14.6 \%$ & النسبة \% & \\
\hline \multirow{2}{*}{ معنوي } & \multirow{2}{*}{ 73.33486 } & 0 & 2 & 0 & 6 & 10 & 26 & 4 & تكرار & \multirow{2}{*}{ الرجلين } \\
\hline & & 0 & $\% 4.2$ & 0 & $12.5 \%$ & $21 \%$ & 54.6 & $8.3 \%$ & النسبة \% & \\
\hline \multirow{2}{*}{ معنوي } & \multirow{2}{*}{60.20959} & 0 & 2 & 0 & 2 & 19 & 18 & 7 & تكرار & \multirow{2}{*}{ طول الفذذ } \\
\hline & & 0 & $4.2 \%$ & 0 & $4.1 \%$ & $39.9 \%$ & $37.8 \%$ & $14.6 \%$ & النسبة \% & \\
\hline \multirow{2}{*}{ معنوي } & \multirow{2}{*}{40.66751} & 0 & 0 & 2 & 6 & 18 & 12 & 10 & تكرار & \multirow{2}{*}{ طول الساق } \\
\hline & & 0 & 0 & $4.2 \%$ & $12.5 \%$ & $37.8 \%$ & $25.2 \%$ & $21 \%$ & النسبة \% & \\
\hline \multirow{2}{*}{ معنوي } & \multirow{2}{*}{51.45941} & 0 & 0 & 3 & 2 & 20 & 13 & 10 & تكرار & \multirow{2}{*}{ عرضفن } \\
\hline & & 0 & 0 & $6.3 \%$ & $4.2 \%$ & $42 \%$ & $27.3 \%$ & $21 \%$ & النسبة \% & \\
\hline \multirow{2}{*}{ معنوي } & \multirow{2}{*}{65.4597} & 0 & 0 & 4 & 1 & 23 & 14 & 6 & تكرار & \multirow{2}{*}{ عرض } \\
\hline & & 0 & 0 & $8.3 \%$ & $2.1 \%$ & $48.3 \%$ & $29.4 \%$ & $12.5 \%$ & النسبة \% & \\
\hline \multirow{2}{*}{ معنوي } & \multirow{2}{*}{54.66781} & 0 & 0 & 3 & 2 & 21 & 13 & 9 & تكرار & عرض \\
\hline & & 0 & 0 & $6.3 \%$ & $4.2 \%$ & $44.1 \%$ & $27.3 \%$ & $18.9 \%$ & النسبة \% & الحوض \\
\hline معنوي & 47.08431 & 0 & 0 & 3 & 5 & 13 & 20 & 7 & تكرار & محيط \\
\hline
\end{tabular}




\begin{tabular}{|c|c|c|c|c|c|c|c|c|c|c|}
\hline & & $\mathbf{0}$ & $\mathbf{0}$ & $6.3 \%$ & $10.4 \%$ & $27.3 \%$ & $42 \%$ & $14.6 \%$ & النسبة \% & العضد \\
\hline \multirow{2}{*}{ معنوي } & \multirow{2}{*}{69.54312} & 0 & 1 & 2 & 2 & 14 & 24 & 5 & تكرار & \multirow{2}{*}{ الحوض محيط } \\
\hline & & $\mathbf{0}$ & $2.1 \%$ & $4.2 \%$ & $4.2 \%$ & $29.4 \%$ & $50.4 \%$ & $10.4 \%$ & النسبة \% & \\
\hline \multirow{2}{*}{ مغنوي } & \multirow{2}{*}{63.70966} & o & 0 & 1 & 4 & 18 & 20 & 5 & تكرار & \multirow{2}{*}{ محيط الفذذ } \\
\hline & & $\mathbf{0}$ & 0 & $2.1 \%$ & $8.3 \%$ & $37.8 \%$ & $42 \%$ & $10.4 \%$ & النسبة \% & \\
\hline \multirow{2}{*}{ معنوي } & \multirow{2}{*}{95.21032} & 0 & $\mathbf{0}$ & $\mathbf{0}$ & 5 & 13 & 28 & 2 & تكرار & \multirow{2}{*}{ ححيط الساق } \\
\hline & & 0 & 0 & 0 & $10.4 \%$ & $27.3 \%$ & $\mathbf{5 8 . 8 \%}$ & $4.2 \%$ & النسبة \% & \\
\hline
\end{tabular}

\section{مناقثة القياسات الجسمية:}

من خلال الجدول أعلاه نلاحظ ان مستوى العينة يتراوح بين المستويين(ضعيف، مقبول) وهذا يدل على ضعف

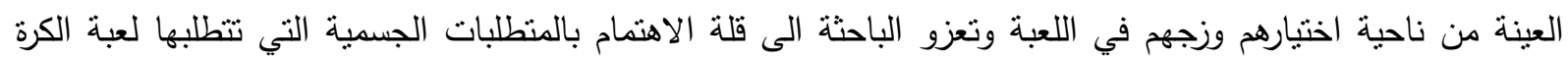

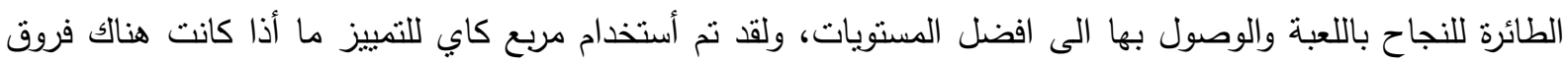

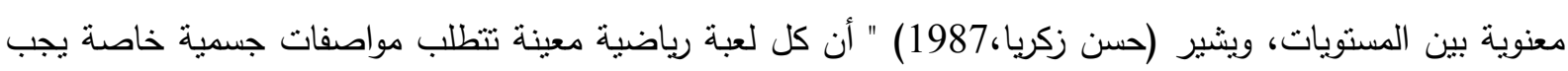

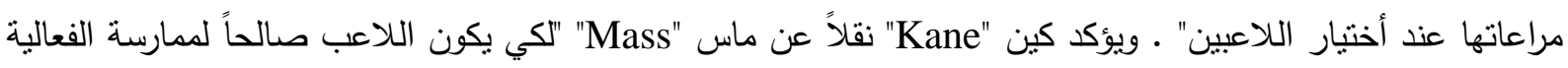

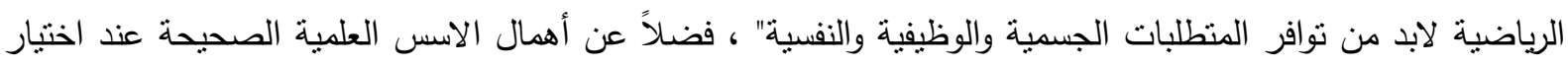

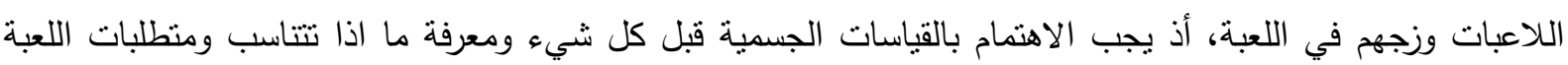

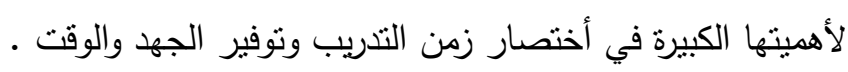
نتائج البحث:

المعايير التي وضعت توصف مستوى القياسات الجسمية . تم التوصل الى ايجاد مستويات معيارية لمتغيرات البحث المتمثلة بالقياسات الجسمية وضمن المستوى ( ممتاز، جيد

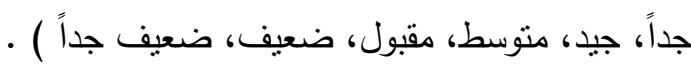

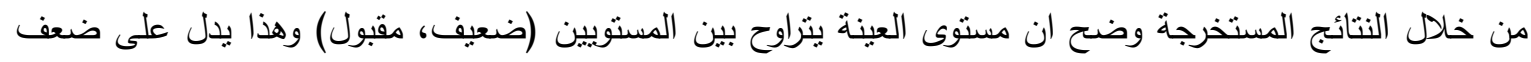
مستوى لعبة الكرة الطائرة النسوية في العراق من الناحية الفنية والتدريبية . من خلال النتائج المستخرجة نلاحظ قلة الاهتمام بالقياسات الجسمية عند اختيار اللاعبات كون لعبة الكرة الطائرة

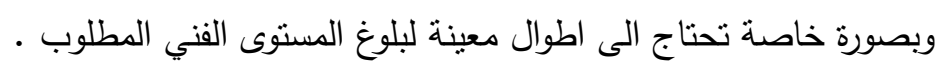
عدم مراعاة التطور الفني الحاصل بمستوى لعبة الكرة الطائرة من ناحية الاجهزة والوسائل التنريبية الحديثة المستخدمة لنطوير الاداء المهاري والبدني.

\section{المصادر}

زكريا محمد حسن ؛ دراسة تحليلية لمستوى الأداء المهاري لبعض فرق الكرة الطائرة المشتركة في الدورة الأولمبية

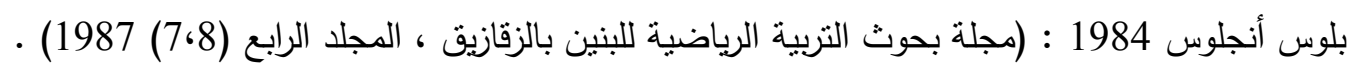

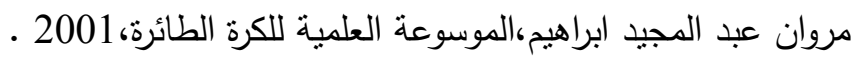
نوري إبراهيم الثوك ـ دراسة تحليلية لمهارتي الأعداد والضربة الساحقة وأثرهما على نتائج المباريات : (المؤتمر

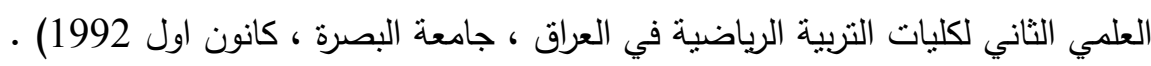

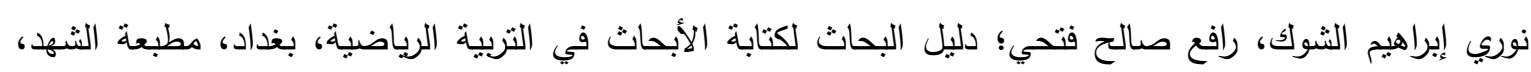
.2004

- Kane J. Epsycholog : Cal. Aspects of physical : (Education and sport kegan 